\title{
Propagation of voltage sags in industrial power networks
}

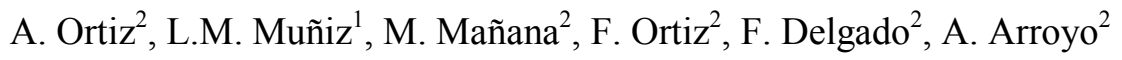 \\ ${ }^{1}$ Automatización y Tecnologías Industriales y \\ Medioambientales S.L. \\ C/La Serna 1B C.P.39311- Cartes (Spain) \\ Phone/Fax number: 0034 942819378/0034 942819111, e-mail atimcantabria@atimingenieria.net \\ ${ }^{2}$ Department of Electrical and Energy Engineering \\ E.T.S.I.I., Cantabria University \\ Avenida Los Castros S/N, 39005 Santander (Spain) \\ Phone/Fax number:0034 942201374/0034 942201385, e-mail: ortizfa@unican.es
}

\begin{abstract}
The paper analyzes the propagation of voltage sags through the distribution network of an industrial company. For this, power quality is monitoring in high voltage, $44 \mathrm{kV}$, and low voltage, $400 \mathrm{~V}$. The theory of $\mathrm{M}$. Bollen is used for the study of the sags recorded by the meters at different points of the installation. It is necessary to know the connection of transformers in order to determine the transmission of the sags.
\end{abstract}

\section{Key words}

Voltage sag, Transformer connection, Industrial loads

\section{Introduction}

One of the typical problems in electrical distribution systems are voltage sags. These have a great incidence on the electrical equipment connected to the network in the same area. The sags cause more damages than the rest of disturbances because these have a greater frequency of occurrence.

During a sag the voltage suffers a sudden reduction between $90 \%$ and $10 \%$. Immediately after a short period of time the voltage recovers its value. Conventionally the duration of a voltage sag is between 10 milliseconds and 1 minute. The voltage sag depth is defined as the difference between the minimum effective value (RMS) during the sag and the reference voltage. Reductions which do not overtake the limit of the $10 \%$ will not be considered as sags.

When monitoring the voltage quality is necessary to take into account that the propagation of disturbances through the power system changeS their characteristics. We can not wait to see the same results in different voltage levels. Industrial loads are usually connected at voltage levels lower than those where the faults occur. Thus, if measured at the substation should be aware that the disturbance will change its characteristics when it comes to load terminals.

The terminal voltages of the loads depend not only on the voltages at the PCC, but also are influenced by the connections of the windings of transformers which are between the PCC and the loads. The voltages at the terminals of the loads also depend on the type of connection to them.

\section{Causes of voltage sags}

\section{A. Shortcircuits and Faults to ground.}

The most common cause of voltage sags are shortcircuits and faults to ground. These cases lead to the more severe voltage falls and to most of the failures in equipment.

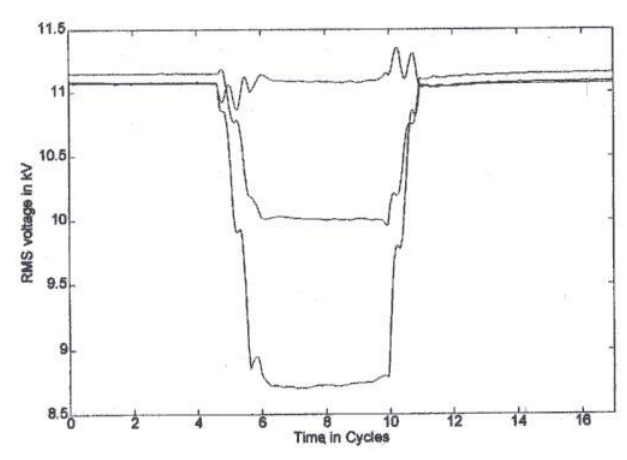

Fig.1 Voltage sag due to a non symmetrical fault.

One example of voltage sag due to fault is shown above. The case of Fig. 1 is associated with different voltage reductions in two phases while the rms value of the other one is not affected by the perturbation. Different effective values in the three phases are a common characteristic in voltage sags caused by faults. Only shortcircuits in the three phases lead to equal values. Another remarkable feature of these cases is the abrupt fall and recovery of 
the voltage; associated with the initiation and the compensation, respectively.

\section{B. Motors and Transformers.}

Starting current of great induction motors is also a cause of voltage sags in power systems. The duration of this type of disturbance is much longer. Voltage sags due to a motor start show a sudden reduction with a slow recovery depending on ratio torque-speed of the load. Since induction motors are a balanced load, the reduction of the rms voltage is the same for the three phases.

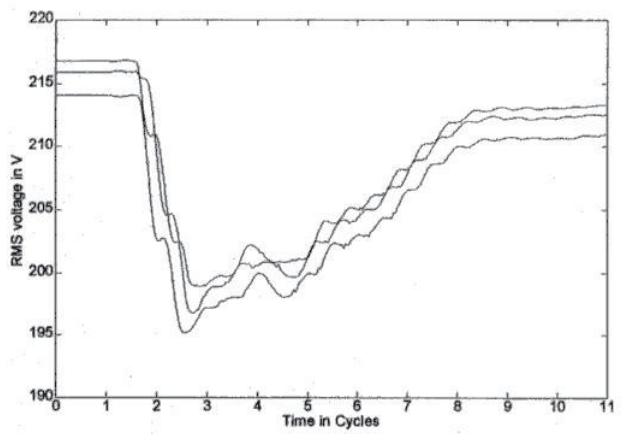

Fig.2 Voltage sag due to a motor starting

Transformers can also provoke voltage sags when they start. The process is characterized by a repetition of short sags with duration of a few milliseconds. These type of events have a great harmonic content. The voltage recovery it is quite slow and it depends on the decomposition of the dc component in the magnetic flux. Different effective values in the three phases are also a common characteristic in voltage sags caused by transformers.

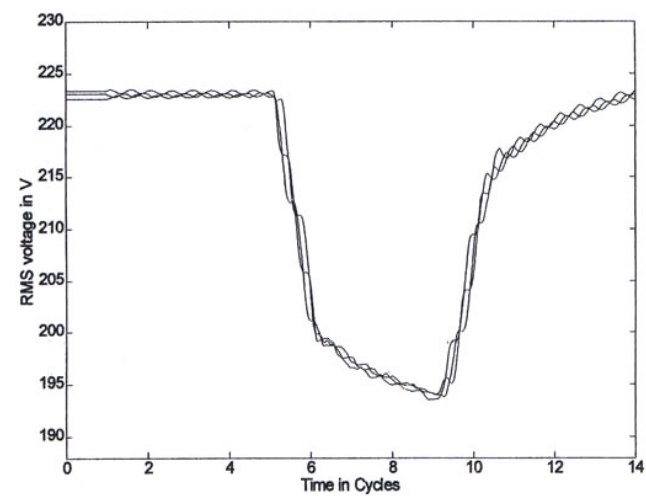

Fig.3 Voltage sag due to a transformer starting

\section{Post-Faults.}

A fault is a very severe disturbance of the power system, affecting as much the distribution as the load, and frequently at large distances. However, in this case the voltage recovery is not complete and does not reach the pre-fault value. The two main causes of Post-Faults are induction motors accelerations and transformers saturation.

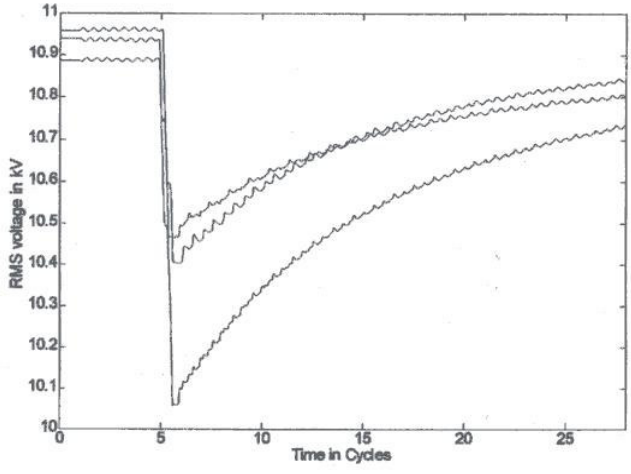

Fig.4 Voltage sag due to a three phase fault

During faults induction motors reduce speed, increasing gradually the current absorbed from the distribution system and causing a deep voltage reduction. These postfaults currents provoke post-faults voltage sags.

\section{Classification of voltage sags}

There are several classification methods for voltage sags:

- Classification using a magnitude.

- Classification using a magnitude and a time period.

- Classification using several magnitudes and a time period.

- Bollen's classification.

In this work the Bollen's classification is used [1]. Seven types of sags are defined which correspond to the possible shortcircuits in the three-phase network and to the sag propagation through transformers. The most common types are A, B, C and D. Their characteristic voltage, by phase, corresponds to the following expressions, Table I:

Table I.- Characteristic voltage for sags A, B,C and D.

\begin{tabular}{|c|c|}
\hline Type 'A' & Type 'B' \\
\hline$V_{a}=V$ & $V_{a}=V$ \\
$V_{b}=-\frac{1}{2} V-j \frac{\sqrt{3}}{2} V$ & $V_{b}=-\frac{1}{2}-j \frac{\sqrt{3}}{2}$ \\
$V_{c}=-\frac{1}{2} V+j \frac{\sqrt{3}}{2} V$ & $V_{c}=-\frac{1}{2}+j \frac{\sqrt{3}}{2}$ \\
\hline Type 'C' & Type 'D' \\
\hline$V_{a}=1$ & $V_{a}=V$ \\
$V_{b}=-\frac{1}{2}-j \frac{\sqrt{3}}{2} V$ & $V_{b}=-\frac{1}{2} V-j \frac{\sqrt{3}}{2}$ \\
$V_{c}=-\frac{1}{2}+j \frac{\sqrt{3}}{2} V$ & $V_{c}=-\frac{1}{2} V+j \frac{\sqrt{3}}{2}$ \\
\hline
\end{tabular}

\section{Propagation of voltage sags across transformers}

The windings of transformers can be connected in different ways, however, only three types summarize the transfer of three-phase unbalanced sags from one voltage level to another [1] 


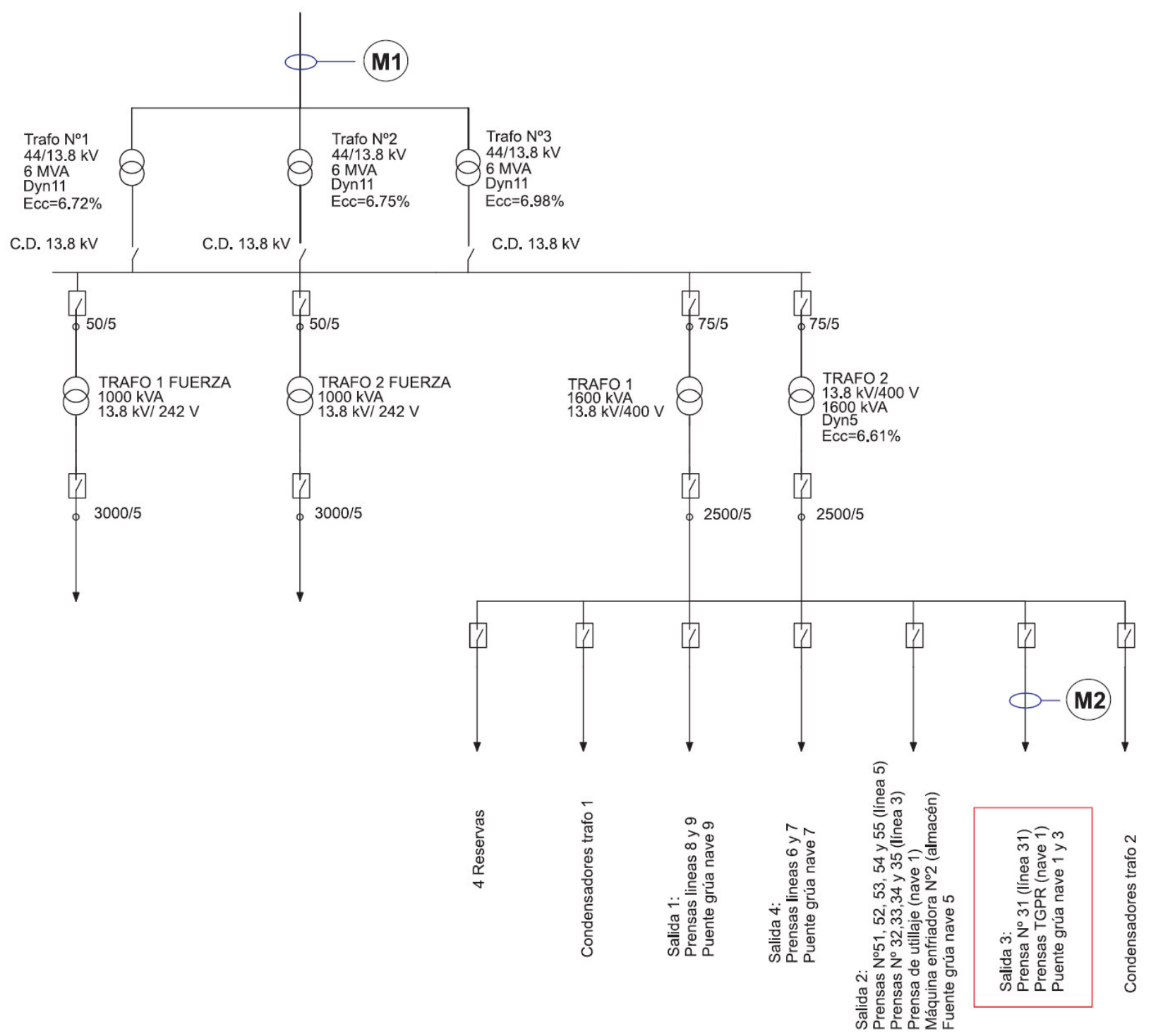

Fig. 5. General view of the electrical circuit under measurement.

1) Transformers that do not change anything to the voltage. Example:Star-star with both star points grounded.

2) Transformers that remove the zero sequence voltage. Example: Star-star with one or both star points grounded.

3) Transformers that change line and phase voltages. Example: Delta-star, Star-delta and Star-zigzag.

The clock number of the transformer connection leads to different phase shift between primary and secondary voltages. However, this has no influence in the equipment suffering the voltage sag.
The origin of sags and the transformation to lower voltage levels, for all seven types of three-phase unbalanced sags, are summarized in Tables II and III.

Table II. - Origin of Three-Phase Unbalanced Sags

\begin{tabular}{|c|c|c|}
\hline Fault Type & Star load & Delta load \\
\hline Three-phase & A & A \\
\hline Two-phase-to-ground & E & F \\
\hline Phase-to -phase & C & D \\
\hline Single-phase & B & C \\
\hline
\end{tabular}

Table III. - Transformation of Sag Type to Lower Voltage Level

\begin{tabular}{|c|c|c|c|c|c|c|c|}
\hline & \multicolumn{7}{|c|}{ Sag on Primary Side } \\
\cline { 2 - 8 } Connection & TypeA & TypeB & TypeC & TypeD & TypeE & TypeF & TypeG \\
\hline YNyn & $\mathrm{A}$ & $\mathrm{B}$ & $\mathrm{C}$ & $\mathrm{D}$ & $\mathrm{E}$ & $\mathrm{F}$ & $\mathrm{G}$ \\
\hline Yy, Dd, Dz & $\mathrm{A}$ & $\mathrm{D}$ & $\mathrm{C}$ & $\mathrm{D}$ & $\mathrm{G}$ & $\mathrm{F}$ & $\mathrm{G}$ \\
\hline $\mathrm{Yd}, \mathrm{Dy}, \mathrm{Yz}$ & $\mathrm{A}$ & $\mathrm{C}$ & $\mathrm{D}$ & $\mathrm{C}$ & $\mathrm{F}$ & $\mathrm{G}$ & $\mathrm{F}$ \\
\hline
\end{tabular}




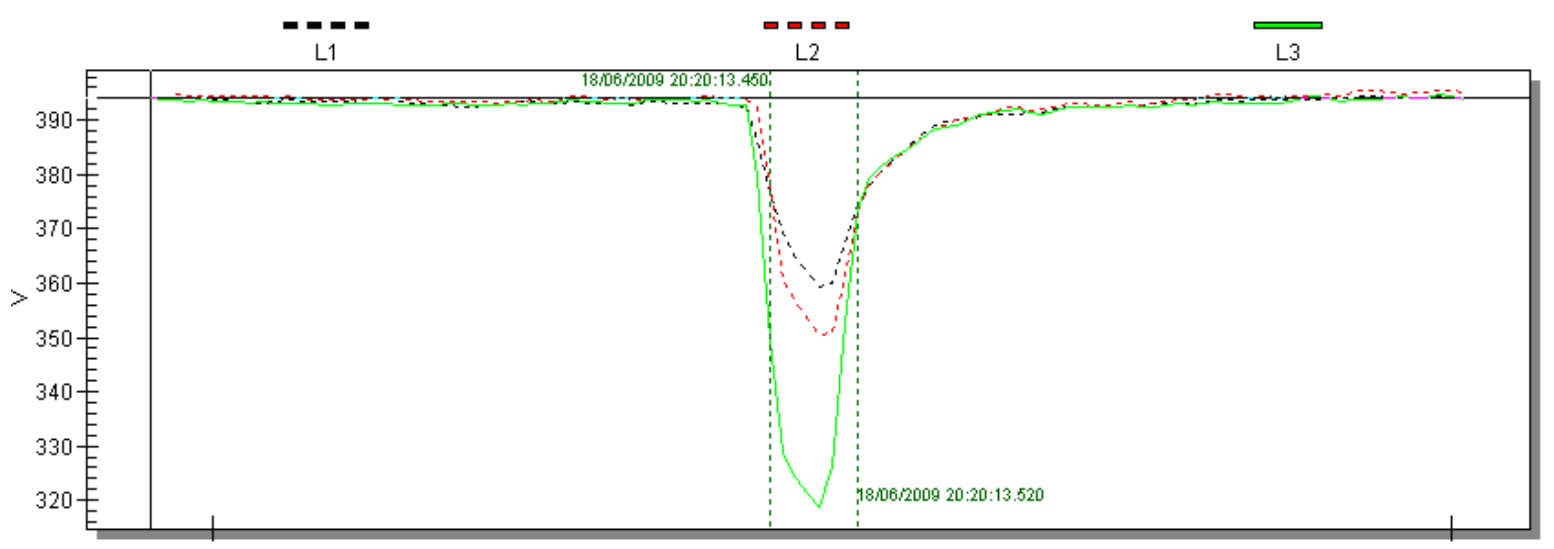

Fig. 6. Low voltage sag (M2).

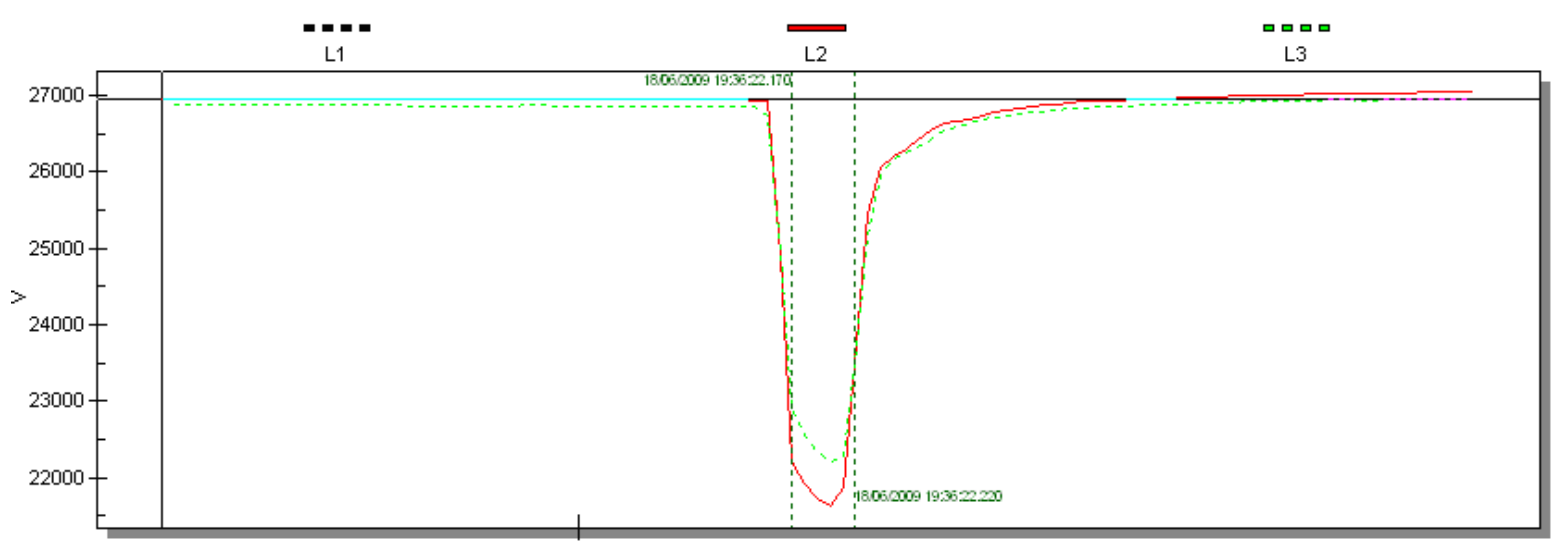

Fig. 7. High voltage sag (M1).

\section{Sags propagation in industrial plants}

Figure 5 shows the electric diagram for the feeding of the factory. The feeding is done from substations at $220 \mathrm{kV}$. The feeding voltage of the plant is performed at $44 \mathrm{kV}$, with a maximum short circuit power $\left(\mathrm{S}_{\mathrm{CC}}\right)$ of about 750 MVA

The industrial plant under study is fed by three transformers ratio $44 / 13,8 \mathrm{kV}, 6$ MVA and Dyn11 connection. The voltage of $13.8 \mathrm{kV}$ undergoes a second reduction ratio through two transformers $13.8 \mathrm{kV} / 400 \mathrm{~V}$, $1600 \mathrm{kVA}$ and Dyn5 connection. At exit number 3, the following loads are located:

1) Press $N^{\circ} 31$ (line 31).

2) TGPR Presses (Building 1).

3) Overhead crane (Building 1 and 3).

Measuring equipment at M1 and M2 points are two QNA 412 Circutor brand, able to record supply quality parameters according to IEC 61000-4-30 Class A.

Figures 6 and 7 show an example of the graphical output of the monitoring software, both in the high voltage and the low voltage measurement points.
Table IV. - Summary of the results classified by sag type.

\begin{tabular}{|c|c|c|c|}
\hline Fault & $\begin{array}{c}\text { High voltage (M1) } \\
\text { Dyn11-Sag1 }\end{array}$ & Sag2 & $\begin{array}{c}\text { Low voltage (M2) } \\
\text { Dyn5-Sag3 }\end{array}$ \\
\hline 1 ph-gnd & $\mathrm{B}$ & $\mathrm{C}$ & $\mathrm{D}$ \\
\hline $2 p h$ & $\mathrm{C}$ & $\mathrm{D}$ & $\mathrm{C}$ \\
\hline $2 p h$-gnd & $\mathrm{E}$ & $\mathrm{F}$ & $\mathrm{G}$ \\
\hline $3 p h$ & $\mathrm{~A}$ & $\mathrm{~A}$ & $\mathrm{~A}$ \\
\hline
\end{tabular}

Table IV summarizes how sags change from high voltage to low voltage, taking into account the winding connections of the transformers and the type of fault that causes the disturbance. The column Sag1 corresponds to what is monitored in the point M1. The column Sag2 corresponds to the type of sag that will appear between both transformers, that is, at $13.8 \mathrm{kV}$. The column Sag3 corresponds to what is monitored in the point $\mathrm{M} 2$, that is, low voltage monitoring.

For a three-phase fault, at any voltage level and for any connection, the sag is type A. For phase-to-phase fault, the load being star-connected, the resulting sag1 is type $\mathrm{C}$, sag2 is type D and sag3 is type $\mathrm{C}$ again. For singlephase faults, there will be a sag1 type B. A star load will suffer a sag2 type $\mathrm{C}$, and a delta load will experience a sag2 type D. For the load connected at low voltage (M2) 
the thing changes: A star load will suffer a sag3 type D, and a delta load will experience a sag3 type $\mathrm{C}$.

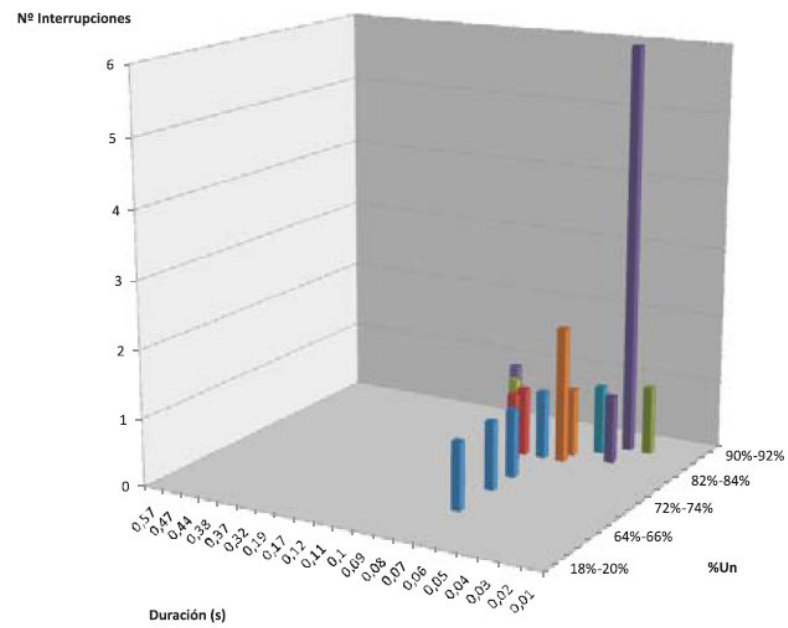

Fig. 8. Summary of sags in the AT side. Year 2009.

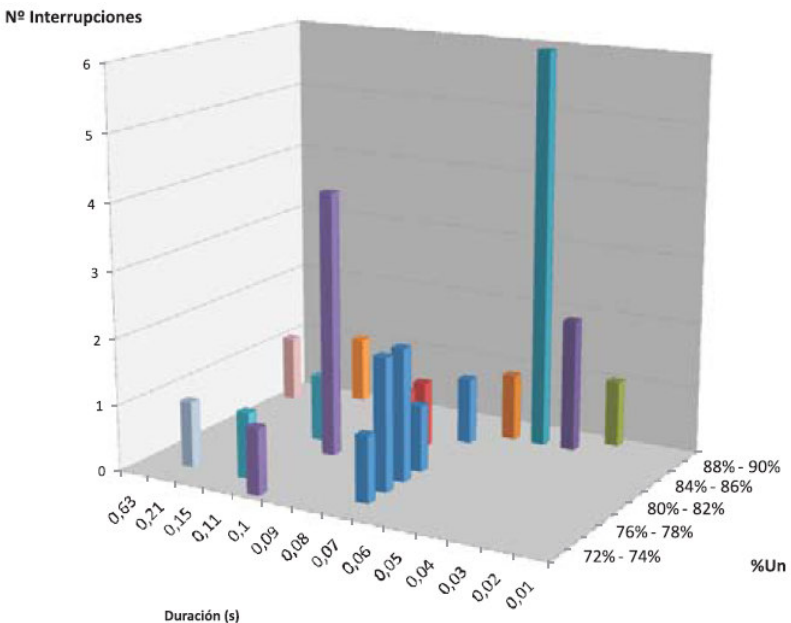

Fig. 9. Summary of sags in the BT side. Year 2009.
M1 Measurement Results

Figure 8 summarizes the distribution of sags in 2009 on the side of AT $(44 \mathrm{kV})$, grouped by duration and amplitude. The most severe sags in the period studied show a depth of $1 \%$ and a duration of seconds.

M2 Measurement Results

Figure 9 shows the summary of sags in the BT side during 2009, grouped by frequency, depth and duration.

\section{Conclusion}

This work studies the actual case of a company, which suffers frequently power quality problems; the transmission of the most common electrical disturbance, voltage sags, which causes major economic losses in the industrial sector. By monitoring two measurement points, the propagation of the sags through the electrical installation will be analyzed, taking into account the theory presented in this subject by M. Bollen.

\section{Acknowledgement}

The authors would like to thank the support of the Spanish Government under the research project ENE2007-68032-C04-04/CON.

\section{References}

[1] M. Bollen, Understanding Power Quality Problems: voltage sags and interruptions, IEEE Press, Piscataway NJ, (2000).

[2] M. Bollen et al. "Assessment of the number of voltage sags experienced by a large industrial customer". IEEE Transactions on Industry Applications, vol. 33, Nov./Dec. 1997.

[3] G. Alonso Orcajo et al." Voltage sags in industrial systems" Proceedings of International Conference on Renewable Energy and Power Quality. Zaragoza, 2005.

[4] UNE 61000-6-2: Compatibilidad Electromagnética (CEM); Parte 6-2: Inmunidad en entornos industriales. 